\title{
A NEW RECORD OF THE GENUS ERotolepsIELLA GIRAULT (HYMENOPTERA: PTEROMALIDAE) FROM THE ORIENTAL REGION WITH DESCRIPTION OF A NEW SPECIES FROM INDIA
}

\author{
T.C. Narendran \\ Systematic Entomology Laboratory, Department of Zoology, University of Calicut, Kerala 673635, India. \\ Email:narendra@unical.ac.in
}

\begin{abstract}
The genus Erotolepsiella Girault is reported for the first time from the Oriental Region with a description of a new species viz.E. indica sp. nov. from India. Its affinities with the known species of the genus are discussed.
\end{abstract}

Keywords

Pteromalidae, Erotolepsiella indica sp. nov., new species, new record.

Abbreviations

Fl to F7 - Funicular segments one to seven

OOL - Ocellocular line

POL - Post ocellar line

STV - Stigmal vein
MV - Marginal vein

PMV - Postmarginal vein

SMV - Submarginal vein

ZSIC - Zoological Survey of India, Regional Station, Calicut

\section{Introduction}

The genus Erotolepsiella was erected by Girault (1915) with the type species Erotolepsiella bifasciata Girault from Queensland, Australia. This is the only species so far described under this genus (Boucek, 1988). This paper reports for the first time this genus from India with a description of a new species. The genus Erotolepsiella Girault belongs to the subfamily Coelocybinae Boucek

\section{Erotolepsiella indica sp. nov.}

(Figs. 1-3)

\section{Material examined}

Holotype: Female, 7.v.1989, Calicut University Campus, Calicut, Kerala, Coll. T.C. Narendran and party. Collection \# IR.INV.854 (ZSIC).

Paratypes: Two females, 7.v.1989, Calicut University Campus, Calicut, Kerala, Coll. T.C. Narendran and party. Collection \# 6102(DST), 6103(DST) (ZSIC).

Received on 4 August 2000

Accepted on 3 January 2001

\section{Distribution}

Malabar area (Kerala) lying between $10^{\circ} 15^{\prime}$ and $12^{\circ} 18^{\prime} \mathrm{N}$ and $75^{\circ} 14^{\prime}$ and $17^{\circ} 56^{\prime} \mathrm{E}$.

\section{Collection method}

The specimens were collected using triangular sweepnet.

\section{Habitat features}

The area from which the specimens of the new species were collected was mixed crop area, mainly pastures.

\section{Current status of habitat}

Disturbed area due to human interference.

\section{Diagnostic features}

Female: Length 1.6-1.8 mm. Head and mesosoma brownishyellow with eye dark brown except pale yellow ring around margin; ocelli pale yellowish-brown; black colour on region near base of hind wing, on sides of frenum, on propodeal crest; hind tibia brown with base and apex paler; gaster black with $\mathrm{Tl}$ and a large band on T2 pale brownish-yellow; epipygium pale brownish-yellow; ovipositor sheath pale brownish-yellow with apex black; forewing with two dark bands (Fig. 1), which are 


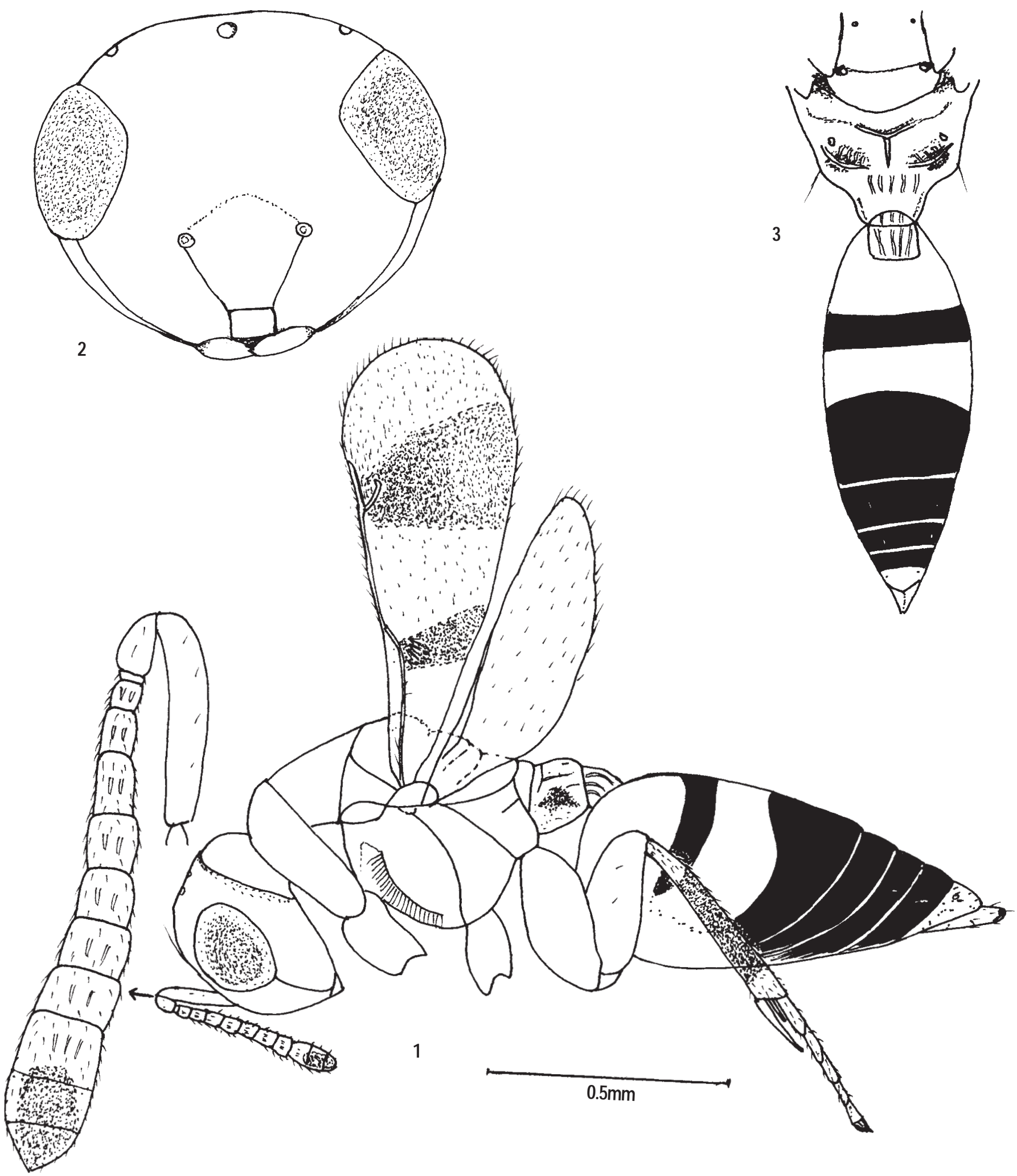

Figures 1-3. Erotolepsiella indica sp. nov. (female)

1. Body profile in part; 2. Head in front view; 3 . Part of scutellum to tip of gaster in dorsal view. 
darker near parastigmal and stigmal areas.

Head: Width in anterior view 1.2x its length (90:75); in dorsal view width $2.5 \mathrm{x}$ its median length; malar sulcus distinct. POL about $3 \mathrm{x}$ OOL; vertex with two pairs of bristles directed forward; vertex with sharp supraoccipital edge; frons and vertex smooth and shiny; clypeus width a little over 1.6x its length; its lower margin entire. Mandibles bidentate. Antenna inserted below level of ventral margin of eye; toruli separated from eye margin a little more than $0.7 x$ that of distance between two toruli; scape not reaching front ocellus, a little over $0.4 \mathrm{x}$ eye diameter, about $3.5 \mathrm{x}$ length of pedicel. Relative measurements of length:width of antennal segments: scape $=41: 7$; pedicel $=12: 7 ; \mathrm{F} 1=5: 5 ; \mathrm{F} 2=8: 7$; $\mathrm{F} 3=12: 10 ; \mathrm{F} 4=10: 9 ; \mathrm{F} 5=10: 10 ; \mathrm{F} 6=10: 12 ; \mathrm{F} 7=10: 13 ;$ clava $=30: 15$ with less sclerotised area containing sensillae; clava as long as length of three preceeding segments combined.

Mesosoma: Pronotum transversely striate with a median transverse carina; mesoscutum and scutellum faintly reticulostriate; mostly smooth under strong light; scapula and axilla with a stronger seta directed posteriorly (setae broken off from the holotype); notauli complete; pubescence sparse; scutellum with two pairs of setae (setae broken off in holotype), posterior pair stronger and lodged on sharp elevated black points on sides of anterior margin of frenum; frenum mostly smooth and shiny. Propodeum with a transverse crest on each side of median 'T'-shaped carina (Fig. 3) containing irregular longitudinal carinulae; with a strong nucha. Forewing length $2.8 x$ its maximum width; with two dark bands, proximal band with a tuft of thick hairs at parastigma. Proximal band not connected with distal band (Fig. 1). Relative lengths of forewing veins: $\mathrm{SMV}=29 ; \mathrm{MV}$ $=22 ; \mathrm{PMV}=9 ; \mathrm{STV}=6$. Hind tibia with two distinct spurs, inner spur stronger and longer than outer spur, longer than hind metatarsus.
Gaster: Smooth, its length a little more than 1.36x length of mesosoma, subequal to combined length of head and mesosoma; petiole length equal to its width; in dorsal view T3 longest.

Male: Unknown

Host: Unknown

Variation: Dark brown colour of holotype is found slightly lighter in paratypes.

\section{Discussion}

There is only one described species under the genus Erotolepsiella Girault, viz. E. bifasciata Girault, which differs from this new species in having: body mainly black with dark metallic tinge (in indica head and mesosoma brownish-yellow); forewing without hair tuft (in indica with hairtuft on proximal fascia); frenal area more coarsely sculputured than rest of the scutulum (in indica, frnal area mostly smooth as in rest of scutulum) and hind coxa deeply reticulate (in indica, hind coxa not deeply reticulate).

This new species shows some generic features of Coelocyboides Girault in having proximal band of fascia of forewing with hairtuft, hind coxa without deep reticulations and body without dark metallic colour.

\section{Acknowledgements}

I thank the authorities of Calicut University for facilities for this research.

\section{References}

Boucek, Z. (1988). Australasian Chalcidoidea (Hymenoptera). C.A.B. International, Wallingford, 1-832.

Girault, A.A. (1915). Some chalcidoid hymenoptera from north Queensland. Canadian Entomologist 47: 42-48. 